\title{
Otyrnomat
}

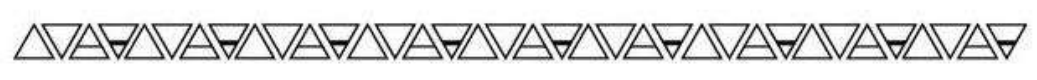

DOI10.31418/2177-2770.2020.v12.n.31.p152-168 | ISSN 2177-2770

Licenciado sob uma Licença Creative Commons

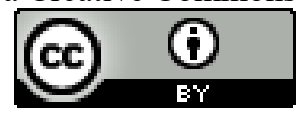

\section{EXPERIÊNCIAS AFRORREFERENCIADAS: A DANÇA NEGRA NO ENSINO FUNDAMENTAL}

\author{
Magali Maria dos Anjos Pintol
}

Resumo: Este artigo visa discutir a importância de experiências afrorreferenciadas para o ensino da dança no contexto da Educação Básica, como contribuição para a educação das relações étnico raciais. Comprometida com o ensino da história e cultura africana, afro-brasileira e indígena, busquei unir o potencial de transformação do ensino da dança a referenciais africanos e afrodiaspóricos. As reflexões apresentadas constituem-se também em um posicionamento político, ético e estético para a valorização da diversidade cultural que contempla a história e a cultura africana, afrodiaspóricas e indígena, a fim de fortalecer lógicas outras de pensar o corpo, a arte e a construção de mundo. Apresento como aportes teóricos: Noguera $(2010 ; 2011)$, Cunha Jr. (2005), Conrado $(2015 ; 2017)$ e Gomes (2005).

Palavras-chave: Experiências Afrorreferenciadas; Dança; Educação; Diversidade étnico racial.

\section{AFRO-REFERENCED EXPERIENCES: BLACK DANCE IN FUNDAMENTAL EDUCATION}

\begin{abstract}
This article aims to discuss the importance of afro-referenced experiences for the teaching of dance in the context of Basic Education, as a contribution to the education of ethnic racial relations. Committed to the teaching of African, Afro-Brazilian and indigenous history and culture, I sought to unite the dance education's potential of transforming to African and Afrodiasporic references. The presented reflections also constitute a political, ethical and aesthetic positioning for the valorization of the cultural diversity that contemplates the African, afrodiasporic and indigenous history and culture, in order to strengthen other logics of thinking about the body, art and construction of the world. I present as theoretical contributions: Noguera (2010; 2011), Cunha Jr. (2005), Conrado (2015; 2017) and Gomes (2005).
\end{abstract}

Keywords: Afro-referenced experiences; Dance; Education; Racial-ethnic diversity.

\section{EXPERIENCIAS AFRO REFERENCIADAS: DANZA NEGRA EN LA EDUCACION FUNDAMENTAL}

\footnotetext{
1 Mestre em Saúde Coletiva pela Universidade Federal da Bahia (UFBA). Bacharel em Medicina Veterinária e Licenciada em Dança, ambas graduações pela UFBA. Pesquisadora do Grupo de Pesquisas Rede Africanidades (UFBA). E-mail: magaslee $@$ gmail.com.br
} 
Resumen: Este artículo tiene como objetivo discutir la importancia de las experiencias mencionadas para la enseñanza de la danza en el contexto de la Educación Básica, como una contribución a la educación de las relaciones raciales étnicas. Comprometido con la enseñanza de la história y la cultura africana, afrobrasileña e indígena, traté de unir el potencial de transformar la educación de la danza en referencias africanas y afrodiaspóricas. Las reflexiones presentadas también constituyen una posición política, ética y estética para la valorización de la diversidad cultural que contempla la história y cultura africana, afroafricana e indígena, a fin de fortalecer otras lógicas de pensamiento sobre el cuerpo, el arte y la construcción. del mundo. Presento como contribuciones teóricas: Noguera (2010; 2011), Cunha Jr. (2005), Conrado (2015; 2017) y Gomes (2005).

Palabras clave: Experiencias afroreferenciadas; Danza; Educación; Diversidad étnica racial.

\section{EXPÉRIENCES AFRO-RÉFÉRENCÉES: LA DANSE NOIRE À L'ÉDUCATION FONDAMENTALE}

Résumé: Cet article vise à discuter de l'importance des expériences afrreference pour l'enseignement de la danse dans le contexte de l'éducation de base, en tant que contribution à l'éducation des relations raciales ethniques. Engagée dans l'enseignement de l'histoire et de la culture africaines, afro-brésiliennes et indigènes, j'ai cherché à unir le potentiel de transformer l'enseignement de la danse en références africaines et afrodiasporiques. Les réflexions présentées constituent également une position politique, éthique et esthétique pour la valorisation de la diversité culturelle qui contemple l'histoire et la culture africaine, afro-africaine et indigène, afin de renforcer d'autres logiques de réflexion sur le corps, l'art et la construction du monde. Je présente comme contributions théoriques: Noguera $(2010 ; 2011)$, Cunha Jr. (2005), Conrado $(2015 ; 2017)$ et Gomes (2005).

Mots-clés: Expériences Afro-référencées; Danse; Éducation; Diversité ethnique-raciale.

\section{INTRODUÇÃO}

A regulamentação das leis 10.639/2003 e 11.645/2008, que atualizam a Lei de Diretrizes e Bases da Educação - LDB 9.394/96 tornando obrigatórios o ensino de História e Cultura das populações africanas, afro-brasileiras e indígenas nas escolas de Educação Básica no Brasil vem contribuir para a valorização da diversidade sociocultural presente em nossa sociedade, de modo a combater o racismo e a discriminação social reproduzidas no ambiente escolar, favorecendo relações harmônicas entre os diferentes.

Cabe destacar que a Lei $n^{\circ}$. 10.639/2003, que altera a LDB 9.394/96 e institucionaliza a obrigatoriedade do ensino de História da África e Cultura AfroBrasileira e Africana nas redes de ensino públicas e privadas é fruto da luta do Movimento Negro, e uma importante conquista para a população brasileira, entretanto nós professores 
precisamos nos responsabilizar por construir novas práticas que estejam comprometidas a valorização da diversidade. Enquanto mediadores da experiência do conhecimento, devemos refletir acerca de nossa postura ética diante da diversidade étnico-cultural e das suas diferentes manifestações no interior da escola.

O enfrentamento do racismo nas escolas é urgente e precisa ser combatido de forma sistemática, institucionalizada e fundamentada teoricamente, pois com profissionais preparados para atuar no fortalecimento da educação das relações étnico raciais torna-se possível, modificar situações observadas que constataram que "Na prática efetiva o que paira na escola é o silêncio diante dos conflitos raciais. Os professores se calam porque não tem subsídios para se posicionar e essa ausência de posicionamento faz com que a criança branca se sinta superior e a criança negra seja considerado inferior" (FRANCO; FERREIRA, 2017, p. 265)

Deste modo, é notório que a formação de professores deve possibilitar embasamentos teóricos, aproximação e valorização das diversas matrizes africanas e afrodiaspóricas, para fins de proporcionar ao profissional em formação experiências que venham a subsidiar práticas pedagógicas que contemplem a diversidade existente na nossa sociedade. Assim, estratégias que fortaleçam a prática docente no sentido de promover uma educação para as relações étnico raciais devem ser discutidas, compartilhadas e atualizadas na esfera da formação inicial, dentro das universidades, e da formação continuada, a cargo de secretarias municipais ou estaduais, corroborando com o entendimento de Franco e Ferreira (2017):

Destaca-se que a formação inicial e continuada são fundamentais para qualificar o trabalho docente e que isso pode ter impactos diretos no processo de implementação da Lei 10. 639/03. Nesse sentido, a Universidade tem um papel significativo, pois cabe à mesma garantir que as discussões sobre as questões étnico-raciais estejam presentes na formação inicial dos estudantes das licenciaturas, o que na prática vem ocorrendo muito lentamente; bem como na formação continuada. Para reverter esse quadro é preciso repensar o currículo dos cursos a fim de incluir disciplinas obrigatórias que tratem dessas temáticas, o que já vem ocorrendo em algumas Instituições (FRANCO e FERREIRA, 2017, p. 263).

Por ter sua atuação também em escolas, professores(as) de Dança devem ter suas práticas pautadas na legitimação de valores culturais dos diferentes grupos étnicos que compõem a nossa sociedade, especialmente quando encontramos resistências embasadas em preconceitos ao propormos atividades que contemplem saberes e práticas 
afrorreferenciadas e que fazem parte da cultura popular brasileira, ou ainda ações racistas direcionadas diretamente para estudantes afrodescendentes. Segundo observação da professora e artista-pesquisadora Amélia Conrado (2017, p. 71):

o conhecimento afro-brasileiro no âmbito da formação acadêmica, sobretudo nas Escolas de Teatro e Dança, Música e Artes Visuais, na universidade pública em Salvador, estado da Bahia, ainda tem sido pouco incorporado aos conteúdos dessas escolas, mesmo com a existência e aprovação de leis de reparação e programas de políticas e ações afirmativas resultantes de nossos processos de lutas sociais (CONRADO, 2017, p. 71).

Em que pese os repertórios de danças africanas, afrodiaspóricas e indígenas, bem como a discussão acerca do tema sejam contemplados na formação em Artes por força dos movimentos sociais - pois ainda que a lei seja dada como implementada, sua efetiva ação por vezes necessita da pressão de estudantes ou do próprio Movimento negro para que seja efetivamente implementada -, muitas vezes as discussões não são acompanhadas de reflexões acerca da prática pedagógica voltada para esta temática. Isto é, mesmo que em nossa formação sejam contempladas as temáticas, não somos provocados a refletir sobre o nosso compromisso ético de assumir dentro das nossas futuras práticas educativas uma postura que contemple a estética negra e indígena.

\section{A REALIDADE DO PROFESSOR}

Adentrar a realidade escolar de modo a atuar e interferir neste contexto, com a possibilidade de discussão e reflexão conjunta para orientação das atividades, proporciona o fortalecimento de nossa atuação enquanto agente mediador de transformações, na medida em que nos motiva a repensar e reinventar o cotidiano escolar, pensando as nossas práticas para além dos muros da escola, de modo que "A nossa meta final como educadores(as) deve ser a igualdade dos direitos sociais a todos os cidadãos e cidadãs" (GOMES, 2005, p.154).

Deste modo, uma vez conhecida a realidade da escola e seu entorno, é possível refletir sobre propostas a serem trabalhadas junto aos estudantes. Em seu texto "A escola reflexiva", Isabel Alarcão (2001, p. 18) chama atenção para o fato de que embora a escola tenha a função de preparar cidadãos, não pode ser pensada como "tempo de preparação para a vida. Ela é a própria vida, um local de vivência da cidadania” . 
Entretanto, segundo Franco e Ferreira (2017), as desigualdades sociais encontram na escola um terreno fértil para se reproduzirem, interferindo na autoestima e construção de identidade de crianças, a ponto de comprometer as relações estabelecidas socialmente. Por esta razão, Silva (2005) nos alerta de nosso papel enquanto professores de Artes em "estabelecer a ponte entre a cultura do educando e a cultura auto denominada 'universal' (a cultura ocidental imposta)" (SILVA, 2005, p. 126-127).

Maria José Silva sugere alguns conteúdos gerais "relativos a Valores, Normas e Atitudes", tais como a "Valorização da própria identidade étnica e cultural e fortalecimento da autoestima" (SILVA, 2005, p.127). Seguindo a lógica africana de não separação das Artes, esta autora nos apresenta uma proposta integrada de Dança e Música, tendo como conteúdos as diversas manifestações populares e afrodiaspóricas, além de danças contemporâneas do universo cultural dos estudantes, e apreciação de vídeos, dentre outras atividades e conteúdos.

A importância de se trabalhar as diversas linguagens de arte integradas como ocorre nas práticas culturais de cosmovisão africana e afrodiaspórica também é compartilhada por Lau Santos, artista-pesquisador, quando ao discutir sobre a presença cênica a partir de princípios afrocentrados, indica que a experiência artística "não deve ser praticada de maneira deslocada, fora dos princípios fundantes que regem as práticas culturais de matriz africana, na qual as linguagens artísticas são compreendidas em sua forma integrada" (SANTOS, 2018, p. 477).

É preciso ressaltar, porém, que são poucas as escolas que contemplam mais de uma linguagem em Artes, de modo que fica a cargo de um mesmo/a professor/a apresentar aos estudantes as diversas linguagens. No entanto, tal fato não deve ser encarado como um sobrepeso para profissionais que buscam atuar dentro de uma perspectiva afrorreferenciada, pois dança e canto - para seguir a proposta de Maria José Silva (2005) - não estão separados nas práticas performativas e culturais africanas e mesmo afrobrasileiras.

Percebe-se, pois, que a Dança enquanto campo de conhecimento não pode mais admitir aulas que abordem exclusivamente técnicas de dança a partir da repetição de movimentos, pois isso seria negar aos estudantes experienciar manifestações diversas de sua própria história e cultura, o que em última instancia se traduz em negar-lhes a própria identidade. Além disso, estaríamos também descumprindo a LDB em vigor. 
No que concerne à Lei n. 10.639-03, o pesquisador Henrique Cunha Jr. nos aponta que:

Tem como principal tarefa fazer a ponte de conhecimentos entre os elementos da História e da Cultura dos afro-descendentes no âmbito local, em cada bairro, em cada município, com os dos estados e regiões, até o âmbito nacional, e destes a um contínuo do passado africano. São elementos da história da humanidade no sentido mais amplo, e têm como principal efeito cumprir o direito que a Constituição nos dá de obter o conhecimento da nossa história e da nossa cultura (CUNHA JR. 2005, p. 269)

Nesse sentido, busca-se aqui discutir experiências afrorreferenciadas visando o conhecimento, a construção e reforço das identidades singulares dos estudantes, dentro das aulas de dança. Busquei unir o potencial de transformação do ensino da dança a referenciais africanos e afrodiaspóricos, em uma proposição de experiências afrorreferenciadas para o ensino da dança, especialmente nas séries do Fundamental I.

Há que se destacar que a utilização de referenciais da cultura africana e afrodiaspóricas é relativamente comum, entretanto, como observa e nos sinaliza Amélia Conrado a partir de sua pesquisa, nem sempre este referencial é creditado e "acreditado".

Revisitando cuidadosamente fatos e história da dança no Brasil, vamos perceber que as elites de dominação ideológica, no campo das artes, apesar de discriminarem a dança popular, considerando-a "incultura", apropriaram-se de seus conhecimentos, reapresentando-a, posteriormente, estilizada, como obras e segmentos renovadores, elaboradores de novos conceitos contemporâneos de arte (CONRADO, 2015, p. 206).

Esta mesma pesquisadora observa ainda que, mesmo a capoeira, "expressão corporal de significativa representação sociocultural da Bahia, que se expandiu pelos cinco continentes", ainda que seja rica em "conteúdos históricos, coreográficos, teatrais, musicais e poéticos, que vem se renovando na dinâmica de nossa sociedade", ainda é pouco utilizada em propostas de encenação (CONRADO, 2015, p. 206). Os princípios da capoeira se mostram um rico campo de metodologias e conteúdos para práticas educativas que visem abordar cooperação em grupo - todos cantam, tocam e lutam -, ritmo, noções de espaço, dentre outros aspectos, permitindo atividades que trabalhem conteúdos mais específicos das artes, mas também valores e atitudes que devem ser reforçadas para a convivência harmoniosa em sociedade.

Sabemos que experienciar e interagir são ações imprescindíveis na área das Artes e principalmente no ensino da Dança em escolas, sobre o qual Isabel Marques (2010) 
explicita e discute sua proposta a partir da abordagem triangular de Ana Mae Barbosa, discorrendo sobre a importância em estabelecer relações entre os conceitos trabalhados, tendo em vista o potencial de transformação do ensino da dança e do lugar da arte dentro da própria sociedade.

Observa-se que a escola enquanto local de formação, embora abarque discursos de valorização da dança e outras práticas corporais e culturais, termina por valorizar e ratificar as habilidades relacionadas às capacidades de leitura e escrita e de cálculo, excluindo o corpo da experiência de ensino-aprendizagem. Ao que Isabel Marques nos aponta que "mais importante do que os conceitos trabalhados são as relações entre eles, pois são as relações estabelecidas que constroem sentidos e significados aos/pelos envolvidos nos processos de ensino-aprendizado de dança” (MARQUES, 2010, p.62).

Dentro do campo da filosofia, Oliveira (2007) propõe o corpo-chão, entendendo o "corpo como território no qual a experiência é a fazedora que constrói e / ou destrói a feitura do próprio corpo. O corpo antecede a experiência como realidade ontológica, mas o corpo não prescinde da experiência" (OLIVEIRA, 2007, p. 102). Tal conceituação nos remete ao processo educativo, e mais ainda ao processo educativo em dança, que tem o potencial de contribuir no desenvolvimento social, psíquico, sensório, cognitivo e motor dos estudantes.

Assim, na busca de uma cosmovisão que privilegie o corpo como ser e lugar privilegiado da experiência, dentro de uma perspectiva afrorreferenciada, recorro inicialmente à afrocentricidade do professor Molefi Asante, o que me permitiu extrair elementos para sulear a proposta de ensino da dança, na forma e no conteúdo, evocando da sabedoria ancestral o entendimento de ser e atuar no mundo.

A afrocentricidade é também apresentada pelo filósofo carioca Renato Nogueira (2010), que parte da indagação acerca da consistência de uma educação afrocentrada. Ao nos apresentar em seu artigo Molefi Asante, responsável por sistematizar o paradigma da afrocentricidade na década de 1980, Nogueira faz uma breve caracterização da afrocentricidade e discute articulações possíveis entre os princípios destas com as Diretrizes Curriculares Nacionais, o que nos aponta, pois, caminhos para uma prática educativa afrorreferenciada na realidade brasileira.

Mais do que uma proposta de educação afrocentrada sistematizada, a "afrocentricidade é um tipo de pensamento, prática, perspectiva que percebe os africanos como sujeitos e agentes de fenômenos atuando sobre sua própria imagem cultural e de 
acordo com seus próprios interesses humanos" (ASANTE apud NOGUEIRA, 2010, p.2).

Assim, os Princípios Asante para o currículo afrocentrado são:

1) Você e sua comunidade; 2) Bem estar e biologia; 3) Tradição e inovação; 4) Expressão e criação artística; 5) Localização no tempo e no espaço; 6) Produção e distribuição; 7) Poder e autoridade; 8) Tecnologia e ciência; 9) Escolhas e consequências; 10) Mundo e sociedade (ASANTE, 2009 apud NOGUEIRA, 2010, p.7)

A partir dos elementos constitutivos de cada princípio, Renato Nogueira buscou a articulação com os Parâmetros Curriculares Nacionais (PCNs) a fim de "enegrecer e sulear práticas pedagógicas em cada disciplina" (NOGUEIRA, 2010, p. 8). Os princípios foram trabalhados nas propostas vezes como conteúdo, vezes como metodologia, de modo que os exemplos trazidos pelo autor facilitam a percepção do leque de possibilidades que tal sistematização permite. Assim, práticas que já são utilizadas, tais como a realização de jogos que não se encerram com a vitória de um indivíduo ou de uma equipe, e jogos cooperativos; confecção de instrumentos musicais africanos; apreciação de artistas e expressões artísticas africanas, dentre outros, quando planejadas dentro de uma perspectiva afrocentrada permite a valorização de aspectos éticos e estéticos oriundos da cosmovisão africana, enaltecendo os saberes africanos e afrodiaspóricos.

O planejamento de aulas de dança a partir do afrocentrismo deve ir além do princípio “4) Expressão e criação artística”, sendo possível abarcar com propostas também outros princípios como o "1) Você e sua comunidade, o 3) Tradição e inovação e o 10) Mundo e sociedade”, devendo a construção da proposta estar aberta ao diálogo com os interesses dos estudantes.

\section{A REALIDADE DO ESTUDANTE}

É comum observar rejeição de parte de estudantes às propostas de danças de matriz africana sob o argumento de que se trata de dança de "macumba". Esta mesma observação se repete quando são apresentadas algumas músicas de brincadeiras populares, como as entoadas em festas de bois. Tudo isso observado em escolas públicas da cidade de Salvador (BA). Observações semelhantes também foram feitas por Oliveira Mion (2018), quando desenvolveu um trabalho com o jongo em uma escola municipal no Espírito Santo: 
Ao investigar o que significa jongo, se, manifestação artístico-cultural ou que outra definição dariam e, qual seria esta consideração, excetuando-se, uma vez mais os integrantes do Grupo de Jongo Mirim "Chrispiniano Balbino Nazareth" que estudam na EMEF "Narciso Araújo", um número expressivo de alunos disse se tratar de macumba, "dança do Bicho Ruim" (OLIVEIRA MION, 2018, p. 252)

Para demonstrar ainda mais a necessidade de o professor de dança ter sua prática comprometida com a educação para as relações étnico raciais, citarei o triste episódio relatado por Nilma Gomes (2005) no qual a comunidade escolar, isto é, diretores, professores, demais profissionais, pais e familiares - presente em uma festa junina permitiram que uma criança negra dançasse com um pau de vassoura "porque nenhum coleguinha queria dançar com um "negrinho" (GOMES, 2005, p. 150).

Percebam que ao me reportar à comunidade escolar presente não pretendo de modo algum minimizar a (ir)responsabilidade da professora que promoveu dentro de uma proposta de confraternização e manifestação popular a exposição de uma criança. Ao contrário, pretendo com estes exemplos ratificar a urgência de que profissionais da Dança estejam mais do que atentas(os), engajadas(os) em promover atividades que contemplem a diversidade étnico racial. Pois sendo a escola "o espaço por excelência onde o patrimônio cultural da humanidade deve ser partilhado, levando em consideração as diferentes culturas que entraram na formação da sociedade, um lugar da participação e do exercício da cidadania" (FRANCO; FERREIRA, 2017, p. 261), o pau de vassoura deve ser "destinado" a todas as crianças - já que temos uma brincadeira conhecida como a "dança da vassoura" na qual todos os participantes devem trocar de par a cada sinal previamente combinado, de modo que quem estiver com o cabo de vassoura também deve ser rápido para deixar seu "par" em busca de outro para dançar. Ou o cabo de vassoura fica sem par, encostado no canto; neste caso, seria melhor promover uma ciranda ou outro tipo de dança já que o grupo de crianças não estava maduro o suficiente para brincar de quadrilha ou poderia a professora ser ela o par, pois uma vez que já passamos pela escola, sabemos o quanto a professora é uma figura cujo acolhimento diz muito a todos do grupo sobre ser preterido(a) ou não. Mais uma vez ressalto que estas linhas não pretendem julgar nem apontar culpados, mas demonstrar como profissionais da Dança podem desempenhar ações importantes e efetivas na valorização da diversidade.

O intuito é também ilustrar como a violência às crianças afrodescendentes pode ser naturalizada e ensinada às outras crianças por todos os adultos que estavam presentes neste episódio. Em pesquisa realizada por Franco e Ferreira (2017), os autores apontam 
a existência de um silêncio dos adultos tanto no ambiente familiar quanto no escolar, reforçando a necessidade e o desafio de uma prática pedagógica promotora da igualdade desde a educação infantil (EI): "É estranho o silêncio gerado em torno destas injustiças, mas ele é revelador do muito que há a fazer para dar voz à problemática das relações raciais nas instituições sociais e educativas, especialmente da EI, e no espaço público, em geral" (FRANCO; FERREIRA, 2017, p. 262).

Aliás, Nilma Gomes (2005) faz uma acertada comparação de anseios quando sentencia que do mesmo modo que nós profissionais da Dança almejamos a valorização de nossa atividade junto aos estudantes no decorrer de todo o ano letivo e não somente em datas festivas, também as temáticas que contemplem práticas antirracistas no interior da escola devem ser discutidas, planejadas e realizadas ao longo do ano letivo - o que ainda não é a realidade das escolas brasileiras, conforme observaram Franco e Ferreira (2017), corroborando com Gomes (2005) sobre eventos isolados e desconexos da realidade dos estudantes:

Logo, apesar da obrigatoriedade legal e da compreensão da importância da Lei, existe uma banalização no processo de implementação da mesma. Apesar do discurso politicamente correto, a questão racial aparece apenas em datas comemorativas (13 de maio, 20 de novembro) ou são experiências pontuais de alguns professores, comprometidos com essa discussão (FRANCO; FERREIRA, 2017, p. 262).

A autora Nilma Gomes (2005) propõe que para trabalharmos em prol da mudança de representações sociais e valores atribuídos aos negros, devemos lançar mão de experiências bem-sucedidas. Isto pode ser feito inclusive articulando-se com outras escolas, organizações sociais, sindicatos ou instituições de formação.

Pautar o Movimento Negro, suas lutas, demandas e conquistas também é proposto por Nilma Gomes (2005), que sugere "um mapeamento das entidades políticas e culturais que trabalham com a questão racial" (p. 153). Aqui gostaria de compartilhar uma proposta que realizei algumas vezes em diferentes turmas de uma escola municipal de Salvador (BA) por ocasião do estágio no Programa Residência Pedagógica (Subprojeto Artes, Núcleo Dança, UFBA) e que se coaduna com a sugestão acima de mapeamento de entidades. Importante destacar que a proposta a seguir apresentada foi adaptada por mim 
a partir de metodologias reunidas em uma tecnologia ${ }^{2}$ de comunicação em saúde elaborada em pesquisa da qual fiz parte.

A proposta se constitui em um mapeamento de equipamentos sociais. A partir da solicitação de um registro (desenhos, questionários, criação de mapas com aplicativos), tal prática permite que os próprios educandos sejam os informantes acerca de espaços públicos ou privados, instituições, estabelecimentos comerciais e pessoas que são referências ou tem reconhecimento dentro da sua comunidade. Assim, mais do que um registro cartográfico, esta proposta pretende valorizar e reconhecer, o sujeito e sua comunidade, ressaltando aspectos que fazem parte das diversas identidades pertencentes ao território e à escola.

Esta proposta é interessante para que o professor conheça um pouco da história de cada estudante e do seu cotidiano, da diversidade cultural e social do grupo, e permite aproximação com aspectos subjetivos do grupo e de sua comunidade. Com esta proposta podemos ainda "mapear" comemorações e festas importantes no bairro em que a escola se encontra. Da mesma forma, também podemos incluir as indagações de Nilma Gomes (2005) acerca de entidades que abordem a questão étnico racial:

Os pais e alunos da comunidade participam de alguma entidade política e cultural que luta contra o racismo e preserva a cultural afro-brasileira? Esse pequeno levantamento poderá levar muitas escolas a descobrirem entidades políticas negras e/ou grupos culturais negros na sua própria região, possibilitando um trabalho integrado entre a escola e a comunidade (GOMES, 2005, p. 153).

Assim, a partir de uma visão afrocentrada, nesta proposta que pode ser realizada com grupos de diferentes faixas etárias, podemos amenizar uma possível ausência de estudos e registros bibliográficos acerca da história e da cultura afrodescendente local, conforme nos alerta Henrique Cunha Jr. (2005), e ainda dar conta de conhecer aspectos sócio culturais dos próprios estudantes, que poderiam ser encobertos por não serem valores e costumes comumente valorizados no âmbito escolar. Lançando mão dos

\footnotetext{
${ }^{2}$ Trata-se do Guia de Comunicação e Saúde: melhorando a interação comunicativa entre profissionais de saúde e comunidade no controle da tuberculose (GCS-Tb), produto de uma pesquisa liderada pela Profa. Dra. Ligia Rangel (ISC-UFBA) da qual fui integrante como pesquisadora voluntária. A pesquisa foi desenvolvida no Distrito Sanitário do Centro Histórico (Salvador-BA), no período de dezembro de 2007 a fevereiro de 2008, a fim de apoiar ações de comunicação no Programa de Controle da Tuberculose. A qualificação do Guia junto a profissionais atuantes foi objeto de uma pesquisa de avaliação também liderada pela Profa. Dra. Ligia Rangel. Desta experiência resultou a minha dissertação de mestrado intitulada Desenvolvimento de competências na abordagem da tuberculose em comunidades: apropriação de uma tecnologia de comunicação em saúde, defendida em 26 -04-13, sob orientação desta mesma professorapesquisadora.
} 
princípios Asante, o mapeamento possibilita abordar elementos que compõem o primeiro, o quinto e o décimo - 1) Você e sua comunidade, 5) Localização no tempo e no espaço, 10) Mundo e sociedade - com possibilidades de desdobramentos para outros princípios. Deste modo, quem propõe esta atividade deve atentar-se para a dinamicidade que lhe é própria, bem como para as possíveis relações que podem ser fortalecidas com família e comunidade, numa atitude de valorização dos saberes e culturas locais.

Por outro lado, podemos citar como um exemplo da não valorização ou distanciamento da realidade cotidiana dos estudantes encontrado no relato de José Oliveira Mion (2019) acerca do jongo de Itapemirim. Segundo relata o autor, apesar de a maioria dos integrantes do jongo mirim estudar na escola municipal em que realizou sua pesquisa, o jongo não era sequer mencionado nas aulas de Artes, e tampouco era praticado pelos outros estudantes, que apresentavam um posicionamento preconceituoso conforme já relatado.

Não temos garantia de que os estudantes nos revelam todos os aspectos de suas vidas sociais, entretanto a proposta de mapeamento é uma investigação que busca oportunizar que eles sejam os próprios contadores de suas histórias, valorizando suas falas e suas práticas, permitindo-nos compartilhar destes saberes dentro da cultura escolar local, conforme indica Henrique Cunha Jr. (2005). O distanciamento relatado acima reflete bem a observação deste pesquisador em relação ao não reconhecimento de determinadas manifestações culturais, conforme se pode ler abaixo:

Para introduzir a cultura afro-descendente, teremos de lidar com a dificuldade de sua amplitude e complexidade. Também com o fato de que as afro-descendências fazem parte das culturas brasileiras de diversas regiões e por vezes perderam as marcas identificadas como de base africana. Muito do que é cultura afrodescendente fica classificado como cultura popular no Brasil, e o popular é visto com desprezo, não é tratado e estudado como componente importante da nossa cultura (CUNHA JR, 2005, p. 266)

Além disso, Amélia Conrado nos alerta para:

A importância, na contemporaneidade, de oferecer estudos e pesquisas sobre matrizes estéticas negro-africanas, negro-brasileiras e educação, permite reunir diferentes contribuições acerca de uma temática que necessita ser investida e devolvida, como um conhecimento de relevância, a comunidades, artistas e universidade (CONRADO, 2015, p. 215) 
Voltando a falar sobre a experiência do mapeamento trabalhada em turmas do ensino fundamental ( $1^{\circ}$. ao $5^{\circ}$. ano), solicitei que desenhassem o bairro no chão da sala utilizando giz colorido a fim de me apresentarem o lugar onde vivem, a partir de indicações como "O que tem próximo de sua casa? Que local você frequenta no fim de semana? Como é o caminho de sua casa até aqui? O que você vê no seu percurso?" A disposição espacial dos desenhos buscou guardar lógica de proximidade ou afastamento de pontos conhecidos, tais como a casa de um colega ou a própria escola. Uma vez o "mapa" desenhado, pode-se sugerir um passeio dançante, com variações de ritmos de acordo com os locais indicados pelos estudantes. Por este motivo, chamei esta atividade de mapeamento dançante.

Durante a atividade, os estudantes se mostraram envolvidos no processo, interessados em mostrar um pouco de sua história de forma lúdica. A partir dos desenhos foi possível reconhecer a importância de alguns equipamentos sociais para aqueles pequenos moradores do bairro, alguns coincidiam com a minha pesquisa prévia acerca da história do bairro, como o parque que outrora era parte da fazenda da qual se originou o bairro; outros aparatos sociais necessitavam de um olhar "de dentro" para emergirem enquanto ilustração, como as igrejas evangélicas desenhadas por algumas crianças.

Assim, essa proposta simples de conduzir e executar pode aproximar o professor da realidade de seus alunos, e ainda indicar possíveis relações que podem ser estabelecidas com os diversos aparatos sociais presentes no entorno da escola. É uma atividade cuja aplicação não se restringe às aulas de dança e permite iniciar discussões sobre valorização e reconhecimento da diversidade étnico racial e cultural, contribuindo para uma educação antirracista e uma prática pedagógica comprometida com o exercício da cidadania e da democracia. Como sugerem Franco e Ferreira (2017):

São estratégias simples que podem ser usadas no cotidiano da escola, construídas a partir dos conhecimentos prévios e dos interesses das crianças, levando em consideração as especificidades locais e com a utilização de recursos normalmente já existentes na própria escola (FRANCO e FERREIRA, 2017, p. 266)

Outras propostas que podem contribuir para a valorização e conhecimento da diversidade cultural que fazem parte da nossa formação podem ser construídas a partir das músicas, sejam as cantigas de rodas, as cirandas, ou cantos populares. É comum que alguns versos do universo infantil façam parte de composições das músicas de algumas 
manifestações populares, de modo que apresentar esta versão dos brincantes pode ser uma maneira de aproximar estudantes deste universo.

\section{CONSIDERAÇÕES FINAIS}

A empreitada de se discutir proposições de experiências afrorreferenciadas para 0 ensino da dança em escolas resultou em uma tarefa com fins de diminuir a distância entre a formação e a realidade demandada. Os diversos textos e autores(as), bem como situações vivenciadas permitiram exercitar a capacidade de criação, adaptação e reflexão acerca das atividades propostas.

Constitui-se também em um posicionamento político, ético e estético para a valorização da diversidade cultural que contempla a história e a cultura africana, afrodiaspóricas e indígena, a fim de fortalecer lógicas outras de pensar o corpo, a arte e a construção de mundo, alternativamente à lógica dominante, racista e eurocêntrica. Conforme afirma Santos (2018):

Reforçamos que a utilização de nomenclaturas vinculadas aos rituais de candomblé, da umbanda, da capoeira e de outras práticas de matriz africana e indígenas no presente estudo é uma estratégia político-pedagógica com orientação decolonial para engendrar princípios da filosofia africana e das cosmogonias afro-brasileiras no campo das artes, particularmente na dança, no teatro e na performance, em oposição a uma hegemonia taxonômica baseada em paradigmas colonialistas eurocentrados (SANTOS, 2018, p. 482).

A metodologia para as aulas de dança ainda que consistam na utilização de jogos e brincadeiras, exploração do espaço, de movimentos cotidianos e do repertório corporal de cada estudante, apreciação de vídeos, experimentação de sequencias de movimentos, composição de coreografia e mostras de dança, deve contemplar também as experiências daquele que aprende, bem como as manifestações culturais populares africanas e afrodiaspóricas.

Franco e Ferreira (2017) propõem algumas estratégias para trabalhar as relações raciais com crianças a fim de promover vivências significativas que permitam o fortalecimento da identidade étnico racial, o resgate da ancestralidade que remonte a brincadeiras antigas, histórias do bairro e de pessoas que fazem parte da história do lugar, valorizando a diversidade e a cultura local, envolvendo a família e todo o entorno da escola. São algumas práticas sugeridas: 
[...] roda de conversa, contação de histórias, utilização de vídeos/filmes, música, desenhos diversos (árvore genealógica, retrato, autorretrato), teatro, brincadeiras com bonecas, atividade de pesquisa, produção de textos coletivos, capoeira, oficina de trançado de cabelo, resgate das brincadeiras, entre outras (FRANCO; FERREIRA, 2017, p.266).

A necessidade de revisitar conceitos estudados, práticas já trabalhadas e refletir sobre a aplicação destes ao processo de ensino-aprendizagem, assim como a de buscar outros aportes teóricos que dialoguem com a realidade encontrada em escolas públicas indica a importância de uma formação voltada para a realidade de um mundo, implicada com a sociedade em que vivemos e com a qual atuamos.

Exatamente nesta busca por aportes teóricos filosóficos que trouxessem uma fundamentação acerca daquilo que ia se conformando como desejo de atuação foi que a necessidade de uma abordagem afrorreferenciada se mostrou emergente no meu caminho enquanto educadora, levando-me a propor atividades de apreciação e experimentação de matrizes estéticas e culturais diversas que se manifestam na arte e na cultura brasileira, sem perder de vista que:

Há de se destacar que, quando escolhemos trabalhar com os saberes e conhecimentos culturais africanos e afro-brasileiros, esse universo é tão amplo quantos forem os países, as regiões, as localidades, os lugarejos, as culturas e as pessoas estudados, tanto da África quanto dos países da diáspora, a exemplo do Brasil, pois esses e outros saberes e conhecimentos se inseriram, definitivamente, constituindo-se elementos essenciais à própria formação da identidade nacional. (CONRADO, 2015, p.203)

Assim, é essencial que processos criativos e de ensino-aprendizagem que visem reforçar a diversidade cultural, contemplando referenciais africanos e afrodiaspóricos e indígenas, atuem dentro de uma perspectiva afrorreferenciada, na qual forma e conteúdo estão imbrincados e dialogam com a realidade dos estudantes. Deste modo, ao contribuir para a construção de identidades étnico raciais positivadas, estaremos promovendo a igualdade dentro das relações sociais e, por conseguinte, fortalecendo a construção do conhecimento. Espera-se com tais práticas despertar o interesse em conhecimentos e saberes identitários estético-corpóreos afrorreferenciados e indígenas, bem como o reconhecimento destes presentes no meio social da escola, além de contribuir para uma formação cidadã com base em princípios estéticos e éticos a partir das aulas de Dança.

\section{REFERÊNCIAS BIBLIOGRÁFICAS}


ALARCÃO, Isabel. A escola reflexiva. In: Artmed Editora. Porto Alegre, 2001, pp. 15-30.

(org). Escola reflexiva e nova racionalidade.

BRASIL. Lei no 10.639, de 9 de janeiro de 2003. Altera a Lei no 9.394, de 20 de dezembro de 1996, que estabelece as diretrizes e bases da educação nacional, para incluir no currículo oficial da Rede de Ensino a obrigatoriedade da temática 'História e Cultura Afro-Brasileira', e dá outras providências. Brasília, DF, jan. 2003. Disponível em: $<$ http://www.planalto.gov.br/ccivil_03/leis/2003/L10.639.htm>. Acesso em: 13 mar. 2019.

BRASIL. Lei n.11.645, de 10 de março de 2008. Altera a Lei 9.394/1996, modificada pela Lei 10.639/2003, a qual estabelece as diretrizes e bases da educação nacional, para incluir no currículo oficial da rede de ensino a obrigatoriedade da temática "História e Cultura Afro-Brasileira e Indígena". Disponível em: < http://www.planalto.gov.br/ccivil_03/_ato20072010/2008/lei/111645.htm >. Acesso em: 13 mar. 2019.

CONRADO, Amélia Vitória de Souza. Artes cênicas negras no Brasil: Das memórias aos desafios na formação acadêmica. Repertório, Salvador, ano 20, n. 29, pp. 68-85, 2017.2. Disponível em: https://portalseer.ufba.br/index.php/revteatro/article/view/25459. Acesso em: 07 mar. 2019.

CONRADO, Amélia Vitória de Souza. Maria Meia Noite: pesquisa cênica afro-brasileira e desafios do processo criativo em dança. Repertório, Salvador, no 24, pp.201-217, 2015.1. Disponível em: $\quad<$ https://portalseer.ufba.br/index.php/revteatro/article/view/14842/10186>. Acesso em: 07 mar. 2019.

CUNHA JR., Henrique. Nós, afro-descendentes: história africana e afrodescendente na cultura brasileira. In: ROMÃO, Jeruse. (org.). História da Educação do Negro e outras histórias. Secretaria de Educação Continuada, Alfabetização e Diversidade. Brasília: Ministério da Educação, Secretaria de Educação Continuada, Alfabetização e Diversidade, 2005, pp. 249-273.

FRANCO, Nanci Helena Rebouças; FERREIRA, Fernando Ilídio da Silva. Pesquisar e educar para as relações étnico-raciais na educação infantil: uma luta contra o ruído do silêncio. Rev. Zero-a-seis, v. 19, n. 36, pp. 252-271, Jul-Dez 2017. Disponível em: https://periodicos.ufsc.br/index.php/zeroseis/article/view/1980-4512.2017v19n36p252 . Acesso em: 07 mar. 2019.

GOMES, Nilma Lino. Educação e relações raciais: refletindo sobre algumas estratégias de atuação. In: MUNANGA, K. (org.). Superando o racismo na escola. Brasília: Ministério da Educação, Secretaria da Educação Continuada, Alfabetização e Diversidade, 2005, pp. 143-154.

MARQUES, Isabel. De tripé em tripé: o caleidoscópio do ensino da dança. IN: BARBOSA, Ana Mae e CUNHA, Fernanda Pereira da. Abordagem triangular no ensino das artes e culturas visuais - memória e história. São Paulo: Cortez, 2010.

OLIVEIRA MION, José Geraldo. Jongo de Itapemirim e sua relação com a educação. Revista da Associação Brasileira de Pesquisadores/as Negros/as (ABPN), v. 11, n. 27, fev. 2019, pp. 230254.

Disponível em http://www.abpnrevista.org.br/revista/index.php/revistaabpn1/article/view/622>. Acesso em: 20 nov. 2019.

NOGUEIRA, Renato. Afrocentricidade e educação: os princípios gerais para um currículo afrocentrado. Rev. África e Africanidades, ano 3, n. 11, nov. 2010. Disponível em: < http://www.africaeafricanidades.com.br/documentos/01112010_02.pdf >. Acesso em: 05 mar. 2019. 
NOGUERA, Renato. Denegrindo a Filosofia: o pensamento como coreografia de conceitos afroperspectivistas. In Griot - Revista de Filosofia, vol. 4, no 2. Salvador: Amargosa, 2011.

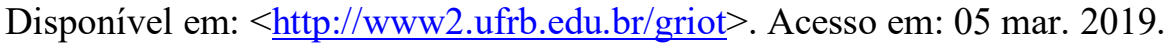

OLIVEIRA, David Eduardo de. Filosofia da ancestralidade: corpo e mito na filosofia da educação brasileira. Curitiba: Gráfica e Editora Popular, 2007.

SANTOS, Lau. Ėmí, Ofò, Asé: A Presença Cênica e a Sutileza Performativa da Dança das "Mulheres do Asé". Anais ABRACE, v. 19, n. 1, 2018, pp. 472-492. Disponível em: https://www.publionline.iar.unicamp.br/index.php/abrace/issue/view/106/showToc. Acesso em: 05 mar. 2019.

SILVA, Maria José Lopes da. As artes e a diversidade étnico-cultural na escola básica. In: MUNANGA, Kabengele. (org.). Superando o racismo na escola. Brasília: Ministério da Educação, Secretaria da Educação Continuada, Alfabetização e Diversidade, 2005, pp. 125-142.

Recebido 30/11/2019

Aprovado em: $30 / 01 / 2020$ 